\title{
Percepção sobre o licenciamento ambiental e expectativas sobre a atuação do Núcleo de Controle Ambiental na etapa de monitoramento no Estado de Minas Gerais
}

\author{
Rosane de Souza Oliveira $^{1}$ e Maria Rita Raimundo e Almeida ${ }^{2}$ \\ ${ }^{1}$ Universidade Federal de Uberlândia. Instituto de Ciências Agrárias. Umuarama. \\ Uberlândia-MG, Brasil (CEP 38400-902). rosanesouza.oliveira@gmail.com. \\ ${ }^{2}$ Universidade Federal de Itajubá (UNIFEI). Instituto de Recursos Naturais. \\ Pinheirinho. Itajubá-MG, Brasil (CEP 37500-903).
}

Resumo. No Brasil, a Política Nacional do Meio Ambiente de 1981 é um importante marco na inclusão das questões ambientais nas políticas públicas e prevê, como um de seus instrumentos, o licenciamento ambiental, que é construído pelas Licenças Prévia, de Instalação e de Operação. Minas Gerais foi um estado pioneiro na utilização do automonitoramento para o acompanhamento dos empreendimentos no pós-licenciamento, porém, enfrenta falhas na sua prática, comprometendo o processo de Avaliação de Impactos Ambientais (AIA). 0 modelo estabelecido pelo Estado na tentativa de superar estes problemas baseia-se na implantação do Núcleo de Controle Ambiental (NUCAM), atuando diretamente nesta etapa. Desta forma, este trabalho teve como objetivo verificar as percepções e expectativas dos servidores do órgão ambiental mineiro com a implementação desse núcleo. Para tal, foram realizadas entrevistas com servidores da Superintendência Regional de Meio Ambiente Triângulo Mineiro e Alto Paranaíba (Supram TMAP). Os servidores da Supram TMAP entrevistados demonstraram acreditar que com a atuação do NUCAM os problemas da etapa de pós-licenciamento irão ser amenizados, porém, é cedo para afirmar que serão sanados. De qualquer modo, o núcleo já se tornou um importante ponto de partida para possibilitar que a AIA cumpra seu papel, sendo necessários futuros acompanhamentos.

Palavras-chave: Pós-licenciamento; Condicionantes; Automonitoramento; Supram.

Abstract. Perception on environmental licensing and expectations on the action of Environmental Control Nucleus in monitoring stage of Minas Gerais State, Brazil. In Brazil, the 1981 Environmental National Policy is an important landmark in the inclusion of environmental issues in public policies and, as one of its instruments, provides for environmental licensing, which is formed by the Preliminary, Installation and Operation Licenses. Minas Gerais State was a pioneer in use of self-
Recebido:

27/11/2018

Aceito:

09/04/2019

Publicado:

30/04/2019

Acesso aberto

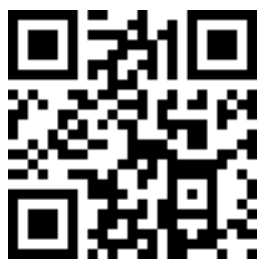

ORCID

(ㄱ) 0000-0001-5964-2719

Rosane de Souza

Oliveira

D 0000-0001-6228-6110

Maria Rita Raimundo e Almeida 
monitoring in follow-up, however, there are many gaps in this practice that compromising the Environmental Impact Assessment (EIA) process. The model established in the attempt to overcome these problems is based on the implementation of Environmental Control Nucleus (ECN), which acts directly at the EIA follow-up stage. In this way, this study had as objective to verify perceptions and expectations of the employees of the environmental agency with the implementation of this nucleus. For that, interviews with Triângulo Mineiro and Alto Paranaíba Regional Superintendence of Environment (TMAP RSE) servers. The TMAP RSE servers interviewed have shown they believe that with the ECN's performance, the problems of the post-licensing stage will be mitigated, but it is too early to say that they will be healed. In any case, the nucleus has already become an important starting point to enable the EIA to fulfill its role and future followups are needed.

Keywords: Follow-up; Conditioning; Self-monitoring; Environmental agency.

\section{Introdução}

No Brasil, a Política Nacional do Meio Ambiente (PNMA), instituída pela Lei no 6.938/1981 (Brasil, 1981) é a principal legislação a tratar da gestão de recursos naturais (Pellin et al., 2011) e deu origem a procedimentos importantes que forneceram as bases para a criação dos 'custos de poluir', entre eles os estudos prévios de impacto ambiental (Drummond, 2001). Estes estudos refletem, na PNMA, a Avaliação de Impactos Ambientais (AIA) e, mais especificamente, o Estudo de Impacto Ambiental (EIA), sendo os principais instrumentos de apoio ao processo decisório, vinculados ao licenciamento ambiental de atividades potencialmente poluidoras e causadoras de significativa degradação ambiental (Oppermann, 2012).

Uma vez assegurada à viabilidade ambiental do empreendimento pelo processo de AIA e deferida às licenças ambientais (a saber, Licença Prévia - LP, Licença de Instalação - LI e Licença de Operação - LO), acontecem às etapas pósdecisão ou pós-licenciamento, que envolvem o processo de monitoramento e o acompanhamento das atividades do empreendimento. 0 objetivo geral do

monitoramento é determinar se os impactos reais de um projeto proposto correspondem aos impactos previstos no EIA (Bard, 2009) e se as medidas propostas são suficientes para a mitigação dos impactos. Além disso, visa a assegurar a implementação da atividade de forma satisfatória e promover ajustes e correções nos procedimentos quando necessário (Almeida, 2013).

O Estado de Minas Gerais foi um dos pioneiros a institucionalizar a AIA (Almeida, 2013) e, segundo Florencio (2010), a utilizar a proposição de condicionantes a serem obrigatoriamente cumpridas pelos empreendimentos potencial ou efetivamente poluidores, para a concessão e renovação das licenças. Uma das condicionantes determinadas é a realização de um programa de automonitoramento que se constitui em um importante instrumento de gestão ambiental, permitindo o acompanhamento e avaliação do póslicenciamento dos empreendimentos.

Entretanto, um dos problemas enfrentados no processo de AIA no Estado é a falha na etapa de póslicenciamento, que é de extrema importância para efetividade do alcance dos seus objetivos, pois é nessa etapa 
que as medidas para mitigar e compensar os impactos significativos identificados no EIA serão implantadas e monitoradas, minimizando as consequências negativas desses impactos ou ainda compensá-los (Santiago et al., 2016).

Como uma medida de solucionar essas falhas do sistema de licenciamento ambiental em Minas Gerais, nessa etapa de pós-licenciamento, em setembro de 2016, foi publicado o Decreto Estadual no 47.042/2016, no qual a Secretaria de Estado de Meio Ambiente e Desenvolvimento Sustentável (SEMAD) cria e dá atribuições ao Núcleo de Controle Ambiental (NUCAM), que tem como uma das suas principais atribuições acompanhar e verificar, nos processos de regularização ambiental em que foi concedida licença de operação, o cumprimento de condicionantes estabelecidas pelo órgão ambiental competente (Minas Gerais, 2016), ou seja, acompanhar o desempenho ambiental dos empreendimentos licenciados no Estado.

De acordo com a Instrução de Serviço do Sistema Estadual de Meio Ambiente (Sisema) no 04/2017, o acompanhamento do NUCAM dar-se-á na fase de operação do empreendimento, com a licença concedida, seja ela LO, Licença de Operação Corretiva (LOC), licenças de operação concomitantes ou renovações e, em caso de descumprimento de condicionantes, caberá ao mesmo notificar o empreendedor a promover as adequações necessárias para o regular cumprimento das condicionantes, bem como a aferição quanto ao atendimento ou não da solicitação e possíveis penalidades (Minas Gerais, 2017).

Desta forma, é importante verificar as perspectivas da implantação do NUCAM e as expectativas futuras sobre o núcleo do ponto de vista dos servidores e, assim, entender como esse núcleo poderá contribuir de forma efetiva na melhoria da etapa de póslicenciamento. Para tal, foram analisadas as opiniões dos servidores da Superintendência Regional de Meio Ambiente Triângulo Mineiro e Alto Paranaíba (Supram TMAP), que também apontaram alguns elementos do atual funcionamento do licenciamento ambiental no Estado.

\section{Metodologia}

A Supram TMAP foi uma das regionais instituídas pelo Decreto $\mathrm{n}^{\mathrm{o}}$ 44.313/2006 (Minas Gerais, 2006), no qual a Semad foi reestruturada, tendo suas atividades descentralizadas para o interior do Estado (Minas Gerais, 2018). Possui sede em Uberlândia com jurisdição sobre 67 municípios: Abadia dos Dourados, Água Comprida, Araguari, Araporã, Arapuá, Araxá, Cachoeira Dourada, Campina Verde, Campo Florido, Campos Altos, Canápolis, Capinópolis, Carmo do Paranaíba, Carneirinho, Cascalho Rico, Centralina, Comendador Gomes, Conceição das Alagoas, Conquista, Coromandel, Cruzeiro da Fortaleza, Delta, Douradoquara, Estrela do Sul, Fronteira, Frutal, Grupiara, Guimarânia, Gurinhatã, Ibiá, Indianópolis, Ipiaçu, Iraí de Minas, Itapajipe, Ituiutaba, Iturama, Lagoa Formosa, Limeira do Oeste, Matutina, Monte Alegre de Minas, Monte Carmelo, Nova Ponte, Patos de Minas, Patrocínio, Pedrinópolis, Perdizes, Pirajuba, Planura, Prata, Pratinha, Presidente Olegário, Rio Paranaíba, Romaria, Sacramento, Santa Juliana, Santa Rosa da Serra, Santa Vitória, São Francisco de Sales, São Gotardo, Serra do Salitre, Tapira, Tiros, Tupaciguara, Uberaba, Uberlândia, União de Minas e Veríssimo (Minas Gerais, 2018).

O NUCAM foi instituído em setembro de 2016 pelo Decreto Estadual no 47.042 e alterado pelo Decreto Estadual no 47.137/2017, tendo como atribuição promover o acompanhamento dos sistemas de controle ambiental dos empreendimentos devidamente regularizados, incluindo cumprimento de condicionantes, autuando e aplicando as 
penalidades previstas pelo descumprimento da legislação ambiental, florestal, de recursos hídricos, pesqueiros e faunísticos (Minas Gerais, 2016; 2017).

Para verificar o papel do NUCAM e as expectativas da implantação desse novo núcleo nas atividades da Supram TMAP de acompanhamento e fiscalização, foram realizadas pesquisas de percepção entre os servidores desta regional. Para tal foram aplicados questionários e entrevistas em fevereiro de 2018, cerca de um ano após a instituição do núcleo.

Foi enviado aos servidores da regional, por correio eletrônico aos endereços institucionais de cada profissional, dos cargos de técnico de meio ambiente, analista ambiental, coordenadores e diretores, um questionário composto por questões que avaliaram a percepção envolvendo 0 trabalho da Supram TMAP e as contribuições que o NUCAM poderá adicionar as atividades desenvolvidas, acompanhado de um breve texto identificando e explicando os objetivos da pesquisa e garantindo o anonimato das respostas.

Aos servidores que atuam diretamente no NUCAM foram realizadas entrevistas semiestruturadas presenciais, nas quais foram elaboradas questões predefinidas dos assuntos a serem abordados como: tempo de trabalho na Semad, cargo que exerce, percepção sobre os aspetos de trabalho dos servidores da regularização e fiscalização, influência de interesses internos e externos, classificação da atuação nas etapas de acompanhamento nessa regional, aspectos ligados à descentralização do órgão ambiental mineiro e expectativas sobre a atuação do NUCAM.

Os resultados obtidos foram tratados em sua totalidade, sem amostragem, e considerados em termos de porcentagem com construção de gráficos para melhor visualização e discussão das respostas obtidas pelos servidores das demais áreas da Supram TMAP. Em relação aos servidores do NUCAM as respostas obtidas nas entrevistas foram redigidas de forma a preservar os pontos citados pelos entrevistados e garantir o anonimato dos mesmos, sendo estes pontos retomados na apresentação e discussão dos resultados.

\section{Resultados e discussão}

A apresentação dos resultados será dividida na percepção geral dos servidores da Supram TMAP, seguida pela percepção dos funcionários diretamente ligados ao NUCAM.

\section{Percepção dos servidores da SUPRAM TMAP}

0 questionário de percepção foi enviado, por correio eletrônico a 42 servidores, sendo quinze analistas da regularização, oito da área jurídica, sete da fiscalização e oito da área administrativa, além de quatro servidores com cargo de chefia.

As respostas obtidas são referentes a dez servidores (o que representa um índice de devolução dos questionários de aproximadamente $25 \%$ ), dos quais um ocupa o cargo de chefia e nove de analista ou gestor ambiental. De acordo com Rahman (2001) e Gomes (2004), é aceitável, para questionários enviados por correio eletrônico, o índice mínimo de $20 \%$ de respostas, portanto, numericamente, o resultado obtido para este trabalho pode ser considerado.

0 tempo médio de prestação de serviços para o Estado dos servidores que responderam ao questionário foi de quatro anos e seis meses, demonstrando que a equipe é composta por profissionais com histórico recente no serviço público e que já ingressaram na Semad após a descentralização ocorrida em 2006.

A Figura 1 ilustra o resultado obtido quando os servidores foram perguntados sobre as condições de 
trabalho dos responsáveis pela regularização e pelo acompanhamento/ fiscalização na Supram TMAP, nos quais

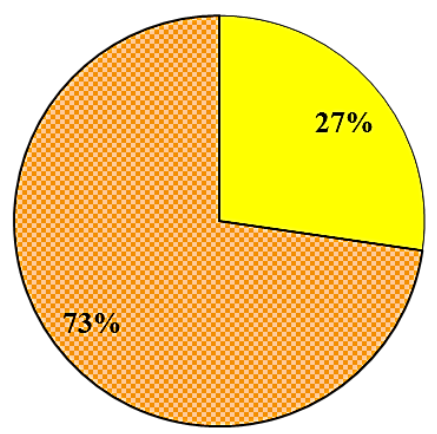

$\mathbf{a}$ os entrevistados deveriam classificá-las em cinco níveis (Excelente, Ótimo, Bom, Ruim e Péssimo).

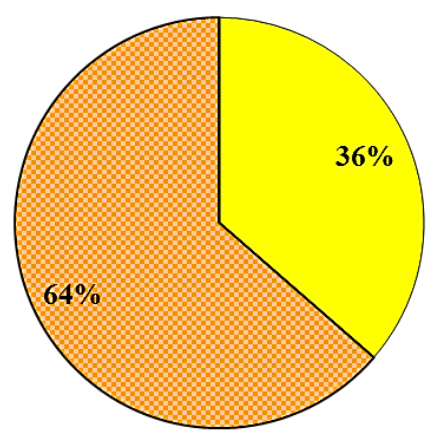

b

\section{Excelente \\ $\square$ Ótimo \\ $\square$ Bom \\ ๑Ruim \\ Péssimo}

Figura 1. Respostas obtidas sobre as condições de trabalho dos servidores da (a) regularização e (b) fiscalização na Supram TMAP.

A maioria dos servidores classificou as condições de trabalho dos responsáveis pela regularização e pelo acompanhamento/fiscalização desta regional como ruim (Figura 1), porém alguns destacaram que se tratando de estrutura física, o espaço de trabalho é satisfatório. No entanto, o que faz com que seja considerado como "Ruim" é, principalmente, a indisponibilidade de informações.

Sobre as questões voltadas às influências externas nos trâmites dos trabalhos realizados na regional TMAP, da importância da fase de acompanhamento e das atribuições do NUCAM, as respostas foram coincidentes. Todos os analistas consideraram que existem influências externas nos trâmites de trabalho da Supram TMAP, fato previsto, pois se trata de um órgão responsável pela decisão de licenciar atividades econômicas que garantem benfeitorias econômicas e sociais para os municípios e para o próprio Estado, refletindo em pressões políticas.

Em relação ao reconhecimento da importância da fase de acompanhamento, é notório que os servidores têm essa consciência, retratada também na informação de que, mesmo não trabalhando no setor, todos sabem as atribuições do NUCAM e 90\% consideram como benéfica a criação deste núcleo. A Figura 2 retrata, ainda, que eles consideram que essa fase do licenciamento tem um desempenho ruim na Supram TMAP. 


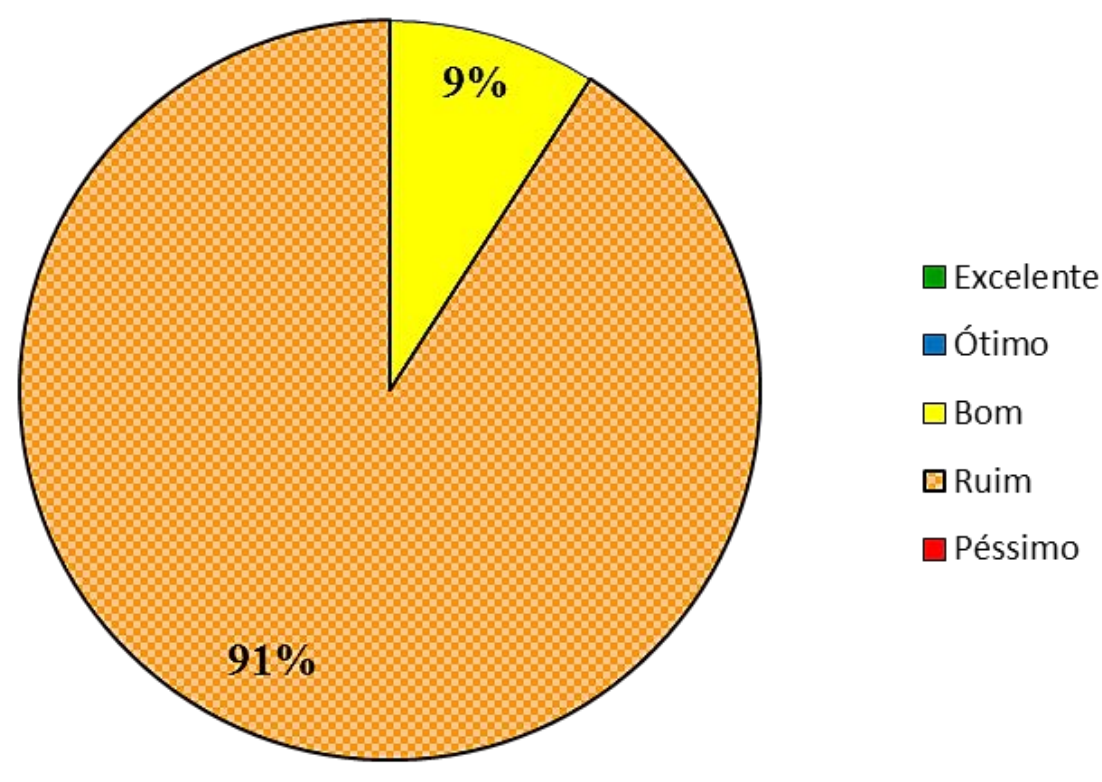

Figura 2. Respostas obtidas sobre como os servidores classificariam o acompanhamento/fiscalização dos empreendimentos pela Supram TMAP.

Sobre o desempenho ambiental dos empreendimentos da região sob jurisdição da Supram TMAP, foi perguntado aos servidores se eles acreditam que o trabalho dessa regional contribui para o bom desempenho ambiental dessas empresas e, mesmo apontando alguns problemas no trabalho realizado pelo órgão ambiental, a maioria concorda que este traz benefícios ao meio ambiente, como visto na Figura 3.

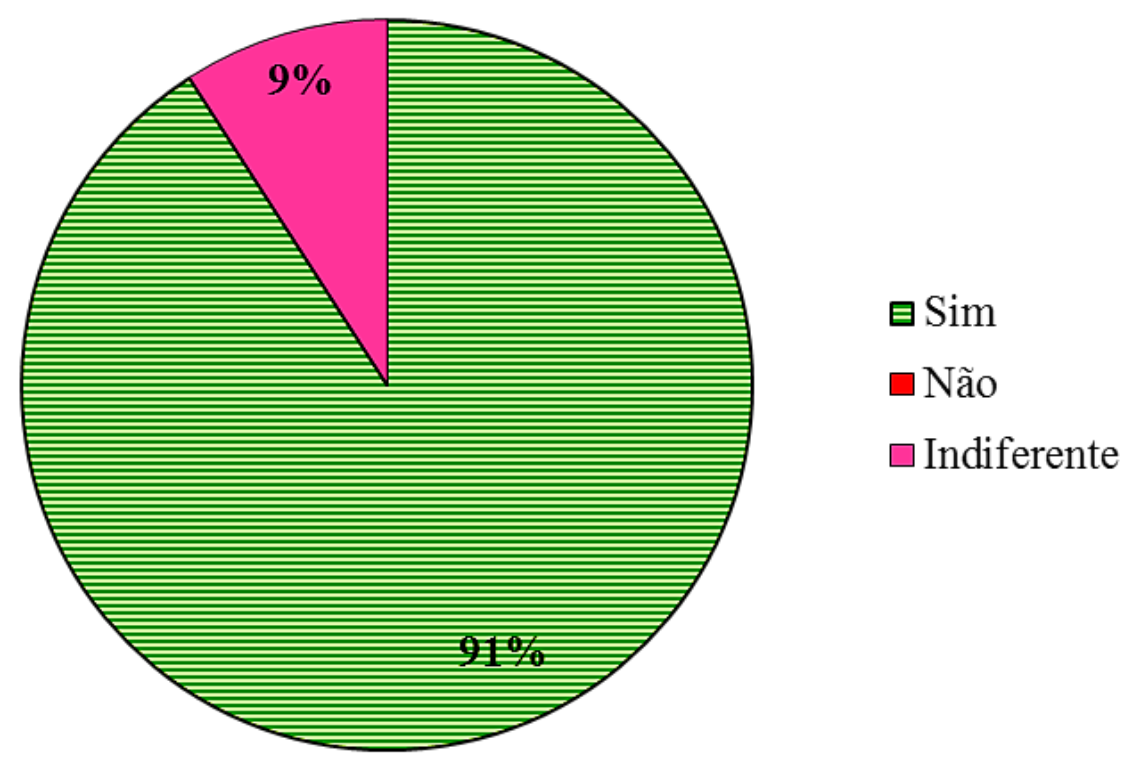

Figura 3. Respostas obtidas sobre a contribuição da Supram TMAP no desempenho ambiental dos empreendimentos. 
Para entender melhor a questão de desempenho ambiental das empresas, foi perguntando qual era o entendimento dos servidores sobre o assunto, sendo apresentado o resultado na Figura 4.

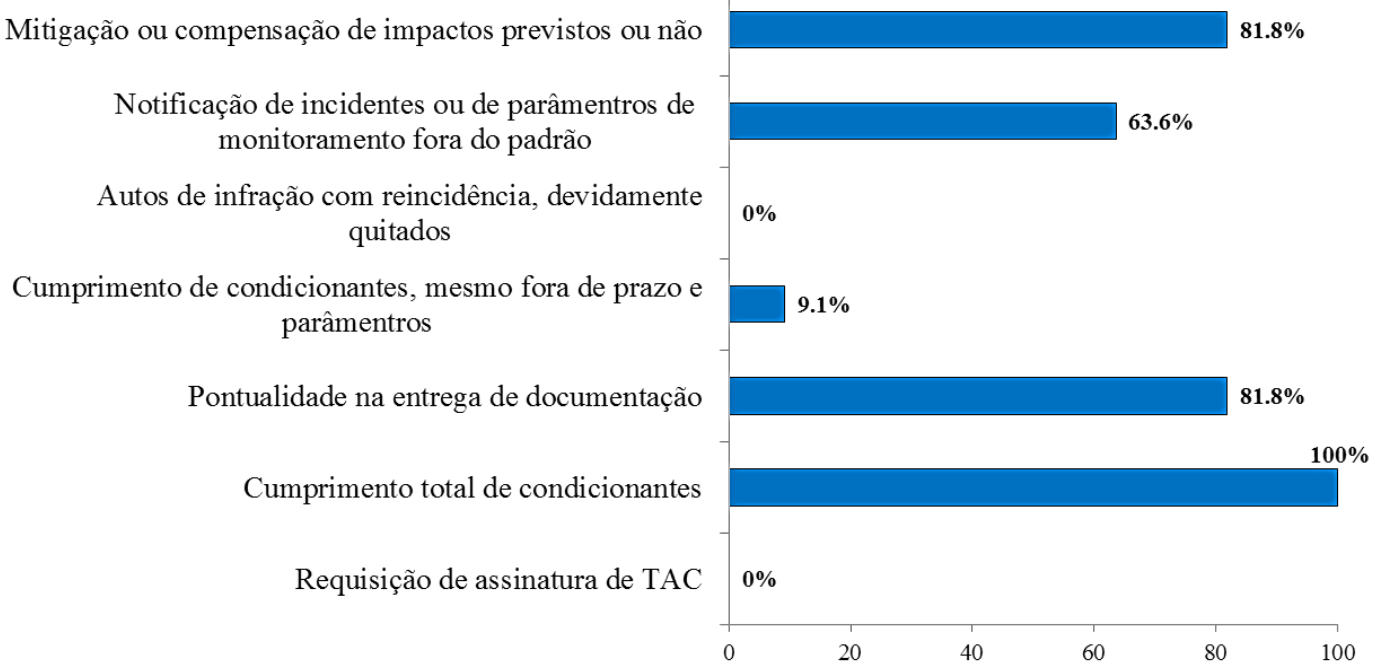

Figura 4. Respostas obtidas sobre indicativos de um bom desempenho ambiental em um empreendimento na opinião dos servidores da Supram TMAP

De acordo com a Figura 4, os servidores da Supram TMAP consideram, na sua maioria, que o cumprimento total de condicionantes, pontualidade na entrega de documentos e a mitigação ou compensação dos impactos previstos ou não são pontos que indicam um bom desempenho ambiental por parte dos empreendedores.

Porém, mesmo 100\% dos servidores considerando o cumprimento de condicionantes um indicativo de bom desempenho ambiental, os estudos relacionados com a etapa póslicenciamento em Minas Gerais, indicam que a conformidade desse item não é observada satisfatoriamente na maioria dos processos (Florencio, 2010; Queiroz e Almeida, 2016; Santiago et al., 2016). Outro ponto de destaque é que $81,8 \%$ dos servidores consideram que um empreendimento ambientalmente adequado deverá mitigar e compensar os impactos ambientais causados pela sua atividade, independente se os impactos foram previstos ou não, entretanto, novamente, estudos indicam que as ações adotadas não são eficientes, não só no Estado, mas no restante do país (Prado Filho e Souza, 2004; Fabri et al, 2008; Florencio, 2010; Mechi e Sanches, 2010; Queiroz e Almeida, 2016; Santiago et al., 2016).

Sobre a descentralização, todos os servidores indicam pontos positivos, principalmente em relação à proximidade com os empreendedores, possibilitando maior regularização e acompanhamento por parte do órgão ambiental, e facilidade de acesso da comunidade atendida pelo órgão.

A aplicação desse questionário, mesmo não sendo respondido por todos os servidores convidados a participar, demonstrou-se importante para entender a dicotomia entre a aplicação e fiscalização das leis ambientais e a falta de estrutura para cumprir com suas atribuições em que os servidores da Semad enfrentam no cotidiano 
profissional, como também relatado por Zhouri (2008).

\section{NUCAM \\ Percepção dos servidores do}

O NUCAM da Supram TMAP era, á época da presente pesquisa, composto por três servidores, dois analistas e um no cargo de chefia do setor. Para aplicar o questionário de percepção a eles, foram marcadas, separadamente, as entrevistas presenciais.

O tempo médio em que estes servidores estão na Semad é de quatro anos e três meses, sendo que o NUCAM foi instituído a cerca de um ano (Minas Gerais, 2016a). Anteriormente ao núcleo, todos eram alocados nas atividades relacionadas à regularização ambiental, também na regional TMAP. Nota-se que, para a formação do Núcleo de Controle Ambiental, o setor de regularização perdeu analistas, o que poderá ser um agravante para o passivo de processos existente no órgão.

Sobre a percepção do atual ambiente de trabalho da regularização e fiscalização, os servidores consideram que o órgão oferece uma boa estrutura física, com frota de veículos em bom estado de manutenção, mesmo em número reduzido, e espaço físico adequado. Porém, destacam os problemas relacionados com falta de acesso à informação e apoio técnico, a defasagem da remuneração dos profissionais quando comparada com o aplicado no mercado de trabalho do setor privado e da questão do escalonamento dos salários aplicado desde 2016 pelo Governo do Estado, além da defasagem do número de servidores em relação à demanda de trabalho e indisponibilidade e defasagem do valor de diárias e combustíveis para as viagens de campo.

Foi levantada, também, a falta de um departamento de Recursos Humanos (RH) na regional, pois mesmo as Suprams sendo autossuficientes, no setor de RH não ocorreu a descentralização, sendo necessário que casos relacionados a este tema sejam reportados a Belo Horizonte; fato este que sobrecarrega os coordenadores e diretores que, muitas vezes, não tem preparo profissional para lidar com questões de relacionamento interpessoal.

Em relação a metas de trabalho, os servidores afirmam que é importante que sejam traçadas, visto que o órgão presta um serviço público de grande responsabilidade, porém, devem ser propostas de acordo com a estrutura da Supram, principalmente em relação ao número de servidores, visto que muitos profissionais já trabalham no seu ápice de produtividade.

Segundo os servidores da Supram TMAP, as influências e pressões por parte dos empresários, políticos e do próprio governo do Estado sofridas na Semad são consideradas naturais ao serviço público e esperadas, visto que o empreendedor sofre perdas econômicas nas suas atividades devido aos trâmites do órgão ambiental, pois existe uma morosidade nas decisões devido ao passivo de processos acumulados. Um dos servidores destacou, ainda, que o setor de regularização é o que mais sofre com essas influências, inclusive, advindas da chefia local ou mesmo da alta hierarquia.

A fase de acompanhamento, na opinião dos servidores entrevistados, é vista como falha, havendo somente fiscalização no momento da renovação da licença ambiental, porém com a instituição do NUCAM esse cenário tende a mudar com o fortalecimento do núcleo e se enxerga um horizonte em que o Estado irá priorizar o acompanhamento em detrimento à regularização.

A simples existência do NUCAM, segundo os servidores, já possibilitou uma mudança de comportamento por parte dos empreendedores, que estão procurando mais por informações de como cumprir suas condicionantes. Foi destacada também a necessidade de alterações na própria legislação ambiental estadual, já que com a iniciada atuação do núcleo foi possível identificar 
pontos que necessitam de atualizações e que estão sendo estudados.

o trabalho do núcleo é organizado juntamente com a Diretoria de Fiscalização, sendo o plano de ação do NUCAM mesclado com o Plano Anual de Fiscalização (PAF). Assim, a equipe divide o atendimento ao PAF, em que é realizada a fiscalização por amostragem, com as requisições do Ministério Público.

Os servidores destacaram como dificuldades, já encontradas no trabalho, a questão de localização dos pareceres e relatórios de automonitomento no arquivo da Supram TMAP, o qual precisa ser reestruturado, e a falta de balizamento entre a regularização e o núcleo. Estão ocorrendo reuniões entre os setores para determinar uma padronização sobre as condicionantes pedidas para cada atividade e a periodicidade na entrega de informações, para que assim não sobrecarregue o arquivo com documentos desnecessários, mantendo um mínimo de exigências que possibilitarão maior agilidade no acompanhamento.

Em relação ao desempenho ambiental dos empreendimentos da área de abrangência da regional TMAP, os servidores acreditam que, com a presença do NUCAM, a tendência é de melhoria, visto que a etapa de póslicenciamento será fortalecida, ou seja, os empreendedores terão que de fato executar os planos de monitoramento e cumprir as condicionantes propostas no tempo adequado.

Já sobre a descentralização do órgão ambiental, foram destacados pontos positivos e negativos: como positivos, a proximidade com o empreendedor e o foco da equipe em uma região; e como negativos a perda da interdisciplinaridade no trabalho e a falta de um mínimo de padronização entre as Suprams.

É notório que os técnicos do órgão ambiental, sejam aqueles que trabalham com regularização ou com fiscalização, estão conscientes das falhas existentes no processo de licenciamento, principalmente na fase pós-licença, porém as respostas e ações para sanar tais problemas caminham a passos lentos e de forma não eficiente como destaca alguns servidores, mesmo porque estas ações, na grande maioria das vezes, deveriam partir de instâncias superiores do governo. Como observado por Cavalcanti (2004), há uma contradição entre os avanços institucionais, de normas e leis e o atraso das suas implementações.

Segundo Fonseca (2018), o Estado brasileiro não tem capacidade de controlar a qualidade ambiental do seu território, faltam recursos nos municípios, estados e União para implementar e manter os instrumentos da Política Nacional de Meio Ambiente, além de capacidade de gestão na implementação destas ferramentas, fazendo com que a burocracia e a falta de eficiência sejam traços marcantes da administração pública ambiental. Enfim, a lacuna entre projeto e sua implementação (pré-decisão e pósdecisão), a deficiência na fiscalização e acompanhamento, a falta de procedimentos mínimos para padronizar o trabalho das Suprams e a falta de estrutura do próprio órgão ambiental para aplicar a legislação estavam presentes nas falas de todos os servidores, assim como constatado por vários trabalhos que estudaram a aplicação da AIA no Brasil (Glasson e Salvador, 2000; Viana, 2007; Zhouri, 2008; Almeida e Montaño, 2015).

\section{Considerações finais}

A aplicação dos questionários e a realização das entrevistas com os servidores da Supram TMAP demonstraram que os técnicos estão cientes das falhas que envolvem $o$ processo de licenciamento ambiental em Minas Gerais, como a lacuna entre o planejamento e a implementação (prédecisão e pós-decisão), a deficiência na fiscalização e acompanhamento, a falta de procedimentos mínimos para 
padronizar o trabalho entre as diretorias da Supram TMAP e a falta de estrutura do próprio órgão ambiental para aplicar a legislação ambiental.

A implementação do NUCAM é vista como uma medida que, mesmo morosa, coleciona boas expectativas entre os servidores que vislumbram, no futuro, melhores resultados para a fase de pós-licenciamento e acreditam, ainda, que 0 Estado poderá adotar procedimentos que garantam melhoria nesta etapa do licenciamento.

É cedo para afirmar que os problemas levantados por vários autores para a etapa de pós-licenciamento serão sanados pela implementação do NUCAM, pois este núcleo carrega os problemas estruturais da Semad, como o número reduzido de servidores, mas já se tornou um importante ponto de partida para possibilitar que a AIA cumpra seu papel. Sendo assim, sugere-se que novas pesquisas sejam realizadas a fim de avaliar o desempenho deste núcleo, já que está pesquisa ocorreu apenas um ano após a implantação do núcleo.

\section{Conflitos de interesse}

As autoras declaram não haver conflitos de interesse.

\section{Referências}

Aledo, A.; García-Andreu, H., Pinese, J. Using causal maps to support ex-post assessmentof social impacts of dams. Environmental ImpactAssessment Review, v. 55, p. 84-97, 2015.

Almeida, M. R. R.. Aplicação da abordagem sistêmica para análise da efetividade da Avaliação de Impacto Ambiental no Brasil: um estudo para os estados São Paulo e Sul de Minas Gerais. São Carlos: Escola de Engenharia de São Carlos, Universidade de São Paulo, 2013. (Tese de doutorado).

Almeida, M. R. R.; Montaño, M. Benchmarking na avaliação de impacto ambiental: o sistema mineiro frente às melhores práticas internacionais. Sociedade \& Natureza, v. 27, n. 1 p. 81-96, 2015. https://doi.org/ 10.1590/1982-451320150106

Arts, J.; Caldwell, P.; Morrison-Saunders, A. Environmental impact assessment follow-up: Good practice and future directions - findings from a workshop at the IAIA 2000 conference. Impact Assessment and Project Appraisal, v. 19, n. 3, p. 175-185, 2001. https://doi.org/10.3152/147154601781767 014

Bard, E. A. Evaluation of the environmental impact assessment system in Egypt. Impact Assessment and Project Appraisal, v. 27, n. 3, p. 193-203, 2009. https://doi.org/ 10.3152/146155109X465959

Cavalcanti, C. Governança ambiental no Brasil: concepção e prática. Anais da XXIV Reunião Brasileira de Antropologia, Olinda, 2004.

Drummond, J.A. Conceitos básicos para a análise de situações de conflito em torno de recursos naturais. In: Bursztyn, M. (Coord.). A difícil sustentabilidade: política energética e conflitos ambientais. Rio de Janeiro: Garamond, 2001. p. 123-147.

Duarte, C. G.; Dibo, A. P. A.; Sánchez, L. E. 0 que diz a pesquisa acadêmica sobre avaliação de impacto e licenciamento ambiental no Brasil? Ambiente \& Sociedade, v. 20, n. 1, p. 245-278, 2017. https://doi.org/10.1590/ 1809-4422asoc20150268r1v2012017

Fabri, E. S.; Carneiro, M. A.; Leite, M. G. P. Diagnóstico dos processos de licenciamento e fiscalização das pedreiras de rochas ornamentais na Região Centro-Sul de Minas Gerais. REM: International Engineering Journal, v. 61, n. 3, p. 279-284, 2008. https://doi.org/10.1590/S0370-446720080 00300003

Florencio, E. O automonitoramento no Estado de Minas Gerais: estudo de caso: Bacia Hidrográfica Do Rio Itabirito. Ouro Preto: Universidade Federal de Ouro Preto, 2010. (Dissertação de mestrado).

Fonseca, A.; Fitzpatrick, P.; McAllister, M. L. Government and voluntary policy making for sustainability in mining towns: A longitudinal analysis of Itabira, Brazil. Natural Resources Forum, v. 37, n. 4, p. 211-220, 2013.

Fonseca, A.; Resende, L. Boas práticas de transparência, informatização e comunicação social no licenciamento ambiental brasileiro: 
uma análise comparada dos websites dos órgãos licenciadores estaduais. Engenharia Sanitária Ambiental, v. 21, n. 2, p. 295-306, 2016. https://doi.org/10.1590/s1413-41522 016146591

Fonseca, A. F. C. Sobre a origem e o futuro das manchetes de crimes ambientais. Direção: Alberto de F. C. Fonseca, Ouro Preto: Observatório de Política Ambiental, vídeo digital (4:50 min), 2018. Disponível em: <https://www.youtube.com/watch?v=F2nccvllsU>. Acesso em: 16 mar. 2018.

Glasson, J.; Salvador, N. N. B. EIA in Brazil: A procedures-practice gap. A comparative study with reference to the European Union, and especially the UK. Environmental Impact Assessment Review, v. 20, n. 2, p. 191-225, 2000. https://doi.org/10.1016/ S0195-9255(99)00043-8

Gomes, R. C. Who are the relevant stakeholders to the local government context? Empirical evidences on environmental influences in the decisionmaking process of English local authorities. Brazilian Admnistration Review, v. 1, n. 1, p. 34-52, 2004.

Mechi, A.; Sanches, D. L. Impactos ambientais da mineração no Estado de São Paulo. Estudos Avançados, v. 24, n. 68, p. 209-220, 2010.

Massoli, E. C.; Borges, F. Q. Análise das externalidades geradas pela Usina Hidrelétrica de Estreito (MA) e o processo de desenvolvimento. Desenvolvimento em Questão, v. 12, n. 28, p. 251-278, 2014.

Minas Gerais. Decreto no 44.313, de 07 de junho de 2006. Dispõe sobre a organização da Secretaria de Estado de Meio Ambiente e Desenvolvimento Sustentável - Semad, e dá outras providências. Disponível em: <http://www.siam.mg.gov.br/sla/download. pdf?idNorma $=5633>$. Acesso em: 15 jun. 2017.

Minas Gerais. Lei no 21.972, de 21 de janeiro de 2016. Dispõe sobre o Sistema Estadual de Meio Ambiente e Recursos Hídricos - Sisema - e dá outras providências. Disponível em: <http://www.siam.mg.gov. $\mathrm{br} / \mathrm{sla}$ /download.pdf?idNorma=40095>.

Acesso em: 02 dez. 2017.

Minas Gerais. Decreto no 47.042, de 06 de setembro de 2016. Dispõe sobre a organização da Secretaria de Estado de Meio
Ambiente e Desenvolvimento Sustentável. Disponível em: <https://www.almg.gov.br/ consulte/legislacao/completa/completanova-min.html?tipo $=$ DEC\&num $=47042$ $\&$ comp $=\& a n o=2016 \&$ texto $=$ consolidado\#tex to $>$. Acesso em: 15 jun. 2017.

Minas Gerais. Sistema Estadual de Meio Ambiente de Minas Gerais. Instrução de Serviço - Sisema. Belo Horizonte: Sisema, 2017.

Minas Gerais. Decreto no 47.137, de 24 de janeiro de 2017. Altera o Decreto no 44.844 , de 25 de junho de 2008, que estabelece normas para licenciamento ambiental e autorização ambiental de funcionamento, tipifica e classifica infrações às normas de proteção ao meio ambiente e aos recursos hídricos e estabelece procedimentos administrativos de fiscalização e aplicação das penalidades. Disponível em: <http://www.siam.mg.gov.br/sla/download. pdf?idNorma=43478>. Acesso em: $04 \mathrm{dez}$. 2017.

Minas Gerais. Secretaria Estadual de Meio Ambiente e Desenvolvimento Sustentável. Triângulo Mineiro. Disponível em: <http://www.meioambiente.mg.gov.br/Supr ams-regionais/Supram-triangulo-mineiro>. Acesso em: 23 jan. 2018.

Oppermann, P.A. Estudo da avaliação ambiental estratégica no Brasil em perspectiva comparada. São Carlos: Universidade de São Paulo, Escola de Engenharia de São Carlos, 2012. (Dissertação de mestrado).

Pellin, A.; Lemos, C. C.; Tachard, A.; Oliveira, I. S. D.; Souza, M.P. Avaliação ambiental estratégica no Brasil: considerações a respeito do papel das agências multilaterais de desenvolvimento. Engenharia Sanitária e Ambiental, v. 16, n. 1, p. 27-36, 2011.

Pinho, T. R. R.; Santos, A. J. C. Passivos socioambientais oriundos de empreendimentos turístico-hoteleiros e seus impactos diretos na base comunitária. Revista Brasileira de Ecoturismo, v. 6, n. 1, p. 297312, 2013.

Prado Filho, J. F.; Souza, M. P. O licenciamento ambiental da mineração no Quadrilátero Ferrífero de Minas Gerais: uma análise da implementação de medidas de controle ambiental formuladas em EIAs/RIMAs. Engenharia Sanitária Ambiental, v. 9, n. 4, 
p. 343-349, 2004. https://doi.org/ 10.1590/S1413-41522004000400012

Queiroz, R. F. P.; Almeida, M. R. R. Mitigação e monitoramento em processos de licenciamento ambiental de empreendimentos sucroalcooleiros no Triângulo Mineiro. Geociências, v. 35, n. 1, p. 102-109, 2016.

Rahman, S. Comparative Study of TQM practice and organization performance of SMEs with and without ISO 9000 certification. International Journal of Quality and Reliability Management, v. 18, n. 1 , p. $35-49$, 2001. https://doi.org/ 10.1108/02656710110364486

Santiago, C. S.; Alvarenga, M. I. N.; Almeida, M. R. R. Avaliação da etapa de acompanhamento do licenciamento ambiental de abatedouros e laticínios em Minas Gerais. Revista Brasileira de Geografia Física, v. 9, n. 3, p. 940-954, 2016.

Viana, M. B. Licenciamento ambiental de minerações em Minas Gerais: novas abordagens de gestão. Brasília: Universidade de Brasília, Centro de Desenvolvimento Sustentável, 2007. (Dissertação de mestrado).

Viana, M. B.; Bursztyn, M. A. A. Regularização ambiental de minerações em Minas Gerais. Revista Escola de Minas, v. 63, n. 2, p. 363369, 2010. https://doi.org/10.1590/S037044672010000200022

Zhouri, A. Justiça ambiental, diversidade cultural e accountability. Revista Brasileira de Ciências Sociais, v. 23, n. 68, p. 97-107, 2008. 